\title{
ANÁLISE DO DISCURSO: LÍNGUA, HISTÓRIA E IDEOLOGIA
}

\section{Maria Virgínia Borges Amaral (UFAL)}

\section{Introdução}

Propomo-nos, neste texto, tratar de discurso, de uma ordem particular de funcionamento da linguagem, distinta da ordem da língua entendida como condição de existência de símbolos, embora seja esta a base comum de todo os processos discursivos. Este trabalho se inscreve no campo da Análise do Discurso (AD) que trata de processos de significação, constituídos pela relação indissociável entre língua e história.

Uma primeira discussão, necessária aos fundamentos do quadro teórico da Análise do Discurso, remete para a compreensão de que o discurso é produzido em um determinado momento históricosocial, é tecido por "milhares de fios ideológicos" (Bakhtin, 1990:86) e responde às necessidades postas nas relações entre os homens para a produção e reprodução de sua existência em sociedade. O discurso é uma materialização das formações ideológicas; é, por isso, o espaço por excelência de expressão da palavra; a instância em que a palavra cumpre sua função, manifestando-se como produto das relações e das forças sociais (Bakhtin, 1992a:66). Entende-se, assim, que o sentido da palavra é constituído no seu encontro com a realidade efetiva, com as circunstâncias da situação social em que foi produzida. O discurso é a instância em que se realiza esse encontro, possibilitando à palavra 'fazer sentido', já que, como afirma Bakhtin (1992b:313), a expressividade da palavra não pertence a ela mesma: "nasce no ponto de contato entre a palavra e a realidade efetiva, nas circunstancias de uma situação real, que se atualiza através do enunciado individual" [grifo nosso]. Ora, assim como a palavra, o discurso não pode ser desvinculado "da situação social mais imediata ou do meio social mais amplo" (Bakhtin, 1992b:113).

Pêcheux (1988:160) também afirma que o sentido das palavras não pertence à própría palavra, não é dado diretamente em 
sua relação com a "literalidade do significante"; "ao contrário, é determinado pelas posições ideológicas que estão em jogo no processo sócio-histórico no qual as palavras, expressões e proposições são produzidas (isto é, reproduzidas)" [grifo nosso]. Então, são as posições ideológicas, que estão em jogo no processo sócio-histórico, que determinam o sentido das palavras.

Essa tese de Pêcheux pode ser tomada como ponto de partida para a reflexão sobre o que é da ordem do discurso. São três os conceitos básicos dessa assertiva de Pêcheux: 'processo sóciohistórico', 'posição ideológica' e 'determinação', que, de alguma forma, se aproximam daquilo que Bakhtin considera como 'realidade efetiva', 'circunstâncias de uma situação real' que determinam o sentido das palavras integrantes do enunciado.

A partir desse conjunto de questões, trataremos de definir a noção de condições de produção do discurso e as instâncias discursivas que, articuladas, tornam possível a produção de efeitos de sentido no processo da enunciação.

\section{As condições de produção do discurso}

Tratar as condições de produção do discurso requer que comecemos por compreender o processo das determinações sociais, políticas e econômicas da produção intelectual em geral, designada pela teoria marxista como formas de consciência ou formações ideológicas. A produção intelectual é concretamente organizada e explicitada em forma de discursos. Isso significa dizer que é como discurso que essa produção intelectual tem efeitos de sentido, atua na realidade e provoca mudanças nas mesmas relações sociais que a originam. Assim, a análise das condições de produção do discurso tanto inclui as determinações históricas desse discurso como os efeitos de sentido que provocam mudanças na realidade em que é produzido.

Tomaremos estes três conceitos - processo sócio-histórico, posição ideológica e determinação - para ingressarmos na discussão do que consideramos uma teoria materialista do discurso, em oposição a uma teoria idealista. Como veremos, esses três conceitos estão tão imbricados que as suas definições serão elaboradas uma em relação à outra, o que, acreditamos, facilitará a compreensão do que pretendemos demonstrar. 
A noção de processo sócio-histórico, aqui, não deverá ser tomada como uma categoria abstrata, mas definida em relação a um modo específico de produção e reprodução da sociedade capitalista. Com essa noção identificamos o processo sócio-histórico em relação a uma sociedade sustentada pelo antagonismo das duas classes fundamentais - capitalistas e trabalhadores -, cuja relação reproduz o processo de dominação do capital sobre o trabalho. Isso posto, poderemos adiantar que a noção de processo sócio-histórico desenvolvida neste estudo está apoiada na seguinte proposição de Marx (1983:24):

Na produção social da sua existência, os homens estabelecem relações determinadas, necessárias, independentes da sua vontade, relações de produção que correspondem a um determinado grau de desenvolvimento das forças produtivas materiais. O conjunto destas relações de produção constitui a estrutura econômica da sociedade, a base concreta sobre a qual se eleva uma superestrutura jurídica e politica e à qual correspondem determinadas formas de consciência social. $O$ modo de produção da vida material condiciona o desenvolvimento da vida social, politica e intelectual em geral. Não é a consciência dos homens que determina o seu ser; é o seu ser que, inversamente, determina a sua consciência.

Embora essa seja uma passagem que trata especificamente do método do materialismo histórico, desenvolvido por Marx, para compreender as relações jurídicas e as formas do Estado, serve-nos como referência para entendermos as condições de produção do discurso porque expõe a relação contraditória entre produção e reprodução da vida dos homens em sociedade.

No debate marxista sobre o método do materialismo histórico, o processo de produção e reprodução da vida dos homens em sociedade foi, muitas vezes, entendido como um "acontecimento histórico", no sentido concebido por Engels: "produto de uma força única, que, como um todo, atua inconsciente e involuntariamente. Pois o que um deseja tropeça com a resistência oposta por outro, e o resultado de tudo isso é algo que ninguém desejava."

Esse entendimento implicou duas noções de determinismo. Uma diz respeito ao determinismo econômico; apóia-se na idéia da

Carta de Engels a Bloch, Londres, 21/22 de setembro de 1890 (Marx e Engels, s/d, v.3, p. 284). 
existência de 'algo' cuja força e poder controlaria ou decidiria "o resultado de uma ação ou processo, além ou apesar das vontades ou desejos de seus agentes" (Williams, 1979:88); esse 'algo' determinante seria a base econômica da sociedade. A outra noção de determinismo remete para a idéia de que o processo de produção e reprodução da vida seria determinado pelas 'vontades individuais'. Nessa interpretação de determinismo, as 'vontades individuais' seriam a única força possível e existente para operar transformações na sociedade, não se considerando que essas 'vontades individuais' também são produtos da história.

Essas interpretações do processo de determinação da produção e reprodução da vida levaram Engels a se posicionar no debate. procurando esclarecer a verdadeira concepção materialista da história. Para essa concepção, a história é determinada pela produção e reprodução da vida real e não se restringe às vontades dos indivíduos. Diz ele:

A situação econômica é a base, mas os diferentes fatores da superestrutura [as formas ideológicas - politicas, juridicas, filosóficas, artisticas] que se levantam sobre ela [...] também exercem sua influência sobre o curso das lutas históricas e, em muitos casos, determinam sua forma, como fator preponderante. (ibidem)

Se considerarmos, como Williams (1979:86), que estrutura e superestrutura, nos termos marxianos, não são "entidades concretas separáveis" em que uma projeta sua força e limita o desenvolvimento da outra, veremos que essa unilateralidade da determinação não se sustenta. A relação entre elas é uma relação processual e histórica, o que revela, no desenvolvimento prático da sociedade, contradições profundas entre as relações de produção e as conseqüentes relações sociais. Se considerarmos, também, que a estrutura econômica é a base real sobre a qual se eleva uma superestrutura jurídica e política, não é difícil compreender que a transformação da estrutura modifica a superestrutura, embora a modificação da segunda nem sempre se dê no mesmo tempo, no mesmo ritmo da primeira. Há, nessa relação, uma contradição que assegura o caráter processual das relações sociais. Os verdadeiros nexos - o antagonismo das classes sociais sobre os quais se sustenta o modo de produção capitalista são dissimulados no embate das duas formas ideológicas básicas - a do capital e a do trabalho - a partir da função que exercem no processo de reprodução e transformação das relações de produção. 
Nesse debate, o que é mais importante não é se existe uma força exterior e independente da vontade dos homens que comanda o seu destino; o mais importante são os "processos reais específicos e indissolúveis" entre a estrutura e a superestrutura, como diz Williams (1979:6): "não é a base (estrutura) e a superestrutura que precisam de estudo, mas os processos reais específicos e indissolúveis". E a relação decisiva dentro desses processos, segundo ele, "é expressa pela noção de determinação".

\subsection{A noção de determinação na teoria da Análise do Discurso}

A noção de 'determinação' introduzida por Pêcheux nos procedimentos teóricos e metodológicos da Análise do Discurso encerra no seu significado uma relação processual, em que não opera, unicamente, um sentido que seria próprio da palavra sobre a constituição do discurso. Também não há o imperativo das 'vontades individuais' em relação ao sentido que essas palavras venham a ter no discurso. O que ocorre no processo de produção do discurso é um complexo processo de inter-relação entre os 'sujeitos falantes' e o meio social (no sentido atribuído por Bakhtin) em que vivem; nessa interrelação os sujeitos sustentam determinadas posições em relação a determinadas formações ideológicas. Por formações ideológicas entenda-se, conforme Pêcheux \& Fuchs (1993:166), uma força capaz de intervir com outras forças, em confronto, em uma dada formação social; "cada formação ideológica constitui um conjunto complexo de atitudes e representações que não são nem 'individuais' nem 'universais' mas se relacionam mais ou menos diretamente a posições de classes em conflito" (ibidem).

As formações ideológicas cumprem sua função na determinação dos sentidos das palavras porque as inscreve nos processos discursivos ${ }^{2}$ das formações discursivas que as representam. As formações discursivas se definem, assim, como espaços de significação que "determinam o que pode e deve ser dito (articulado sob a forma de uma arenga, um sermão, um panfleto, uma exposição, un programa etc.) a partir de uma posição [ideológica] dada numa conjuntura" (Pêcheux, 1988:160). É no interior das formações

Conforme definido por Pêcheux (1988:161), "o sistema de relações de substituição, paráfrases, sinonímias etc., que funcionam entre elementos lingüísticos - 'significantes' - em uma formação discursiva dada". 
discursivas, pois, que os sujeitos podem manifestar as posições ideológicas que ocupam no meio social, mesmo que nessas posições esteja ocultada para o sujeito a fonte do seu dizer ${ }^{3}$. Essa posição do sujeito é marcada por um efeito de 'onisciência' da subjetividade, produzida pela intervenção da ideologia de cunho idealista, que enaltece o sujeito como fonte do processo de produção e reprodução da vida, e, portanto, das suas formas de representação: o sujeito tem a ilusão de que é dono do seu discurso (esquecimento 1) e que tem a autonomia na escolha das palavras que emprega no discurso que julga ser seu (esquecimento 2) (Pêcheux, 1988/1993).

Isso significa dizer, como Bakhtin (1992b:313), que cada época, cada momento histórico, cada uma das esferas da vida tem 'saberes' já sedimentados e "acatados que se expressam e se preservam sob o invólucro das palavras, da obras, dos enunciados, das locuções etc." É por isso que os 'dizeres' do 'sujeito-falante' tomam forma e evoluem sob o.efeito da relação contínua e permanente com outros enunciados já ditos nas mais diversas instâncias de enunciação ${ }^{4}$. Então, embora os processos discursivos, compreendidos como relações de paráfrases inerentes à formação discursiva (Pêcheux \& Fuchs, 1993:170), não tenham origem no sujeito, só podem se realizar no e com esse sujeito, porque só ele pode dar voz à 'mudez do real's, só o sujeito é capaz de elaborar representações desse real, o que significa reconhecer que ao produzir discursos o sujeito imprime sua marca, tomando a palavra como "a sua palavra", através da qual pode se expressar, se fazer entender e se identificar enquanto sujeito no
mundo.

Assim, a noção de determinação, segundo entendemos, tanto expressa a fixação dos limites do sentido das palavras, estabelecendose as fronteiras entre os processos discursivos de uma formação

Adiante veremos mais sobre as noções de formação ideológica e de formação discursiva.

4 Configurando-se a cadeia da interação verbal, no sentido empregado por Bakhtin (1992a:123): um fenômeno social que constitui a realidade fundamental da língua, visto que não pode haver enunciado isolado; ele "sempre pressupõe enunciados que o precederam e que the sucederam", formando uma 'cadeia' (idem, 1992b:375).

5 Referimo-nos, de forma muito genérica, ao papel da linguagem na reprodução intelectiva do real, e, conseqüentemente, a sua função no processo de produção e reprodução da vida (Chasin, 1982). 
discursiva e de outra, como permite a polêmica, o debate com a exterioridade do discurso (interdiscursos). Essa noção possibilita a compreensão do processo de produção de noṿos sentidos atribuídos a uma palavra em relação aos sentidos já existentes, constituindo-se numa inesgotável relação entre discursos que representam uma ou mais formações ideológicas.

Entendido o processo de determinação do sentido das palavras, expressões ou proposições de um discurso em relação ao processo sócio-histórico e às formas ideológicas a esse processo correspondentes - políticas, jurídicas, filosóficas, artísticas -, podemos compreender que um discurso é constituído/constitutivo nesse e desse processo: tanto o discurso (como um espaço das manifestações das formações ideológicas) é determinado pelo processo sócio-histórico, como exerce influências sobre ele. De maneira que, considerando-se que todo discurso é, por natureza, ideológico, a sua análise implica necessariamente o entendimento daquilo que expressa através do seu processo discursivo, na relação que mantém com a 'situação concreta' (a posição ideológica) do sujeito que o expressa. Dizendo de outro modo, o discurso é resultado de um amplo e complexo processo de constituição do sujeito pela ideologia, sendo por isso que as expressões desse sujeito já não são expressões de um 'indivíduo singular', mas de um 'sujeito histórico' que se define em relação às formações ideológicas de uma dada formação social. $\mathrm{O}$ indivíduo é "sujeito" na medida em que é transfigurado pelo histórico, pela força que a ideologia exerce sobre sua constituição (Chasin, 1978:66-73), e o discurso é ideológico porque tanto representa um produto do processo de constituição do sujeito histórico, resultado da interpelação ideológica, como opera no sentido de contribuir com a continuação desse processo de 'formação' do sujeito.

As condições de produção de um discurso, pois, estão relacionadas à totalidade do processo sócio-histórico, um processo social em movimento que supõe indivíduos em relação com a cultura, a sociedade, a economia, tudo isso constituindo a substância da história. O que se destaca na noção de condições de produção não é a situação empírica, as circunstâncias imediatas que constituem o 'contexto' no qual o discurso foi produzido; é a representação da 
situação empírica no imaginário ${ }^{6}$ histórico-social, a "exterioridade constitutiva do discurso". Não se compreende, então, o discurso separado da sua 'exterioridade constitutiva', "no discurso há sempre um discurso outro, função da relação do todo com a ideologia (com a exterioridade, com o interdiscurso)" (Orlandi, 1996:11). O que está em discussão com a noção de condições de produção do discurso é, na verdade, o movimento do discurso, os seus nexos, o que faz o discurso ser o que é; em suma, a sua dialética.

\subsection{Língua e História}

$\mathrm{Na}$ perspectiva da Análise do Discurso não se concebe a 'existência' de uma dimensão de exterioridade do discurso como sendo o extralingüístico e outra de interioridade como sendo o lingüístico. A exterioridade do discurso, para a $\mathrm{AD}$, corresponde aos discursos já existentes e com os quais o discurso se constitui como um outro discurso; trata-se do processo entre discursos - o interdiscurso, ${ }^{7}$ que, como diz Maingueneau (1993:54), não tem "uma relação de exterioridade", uma relação que se consubstanciaria por um encontro entre duas coisas distintas: a exterioridade ou "realidade histórica" e a interioridade, o lingüístico ordenado em discurso.

- O imaginário é, nessa perspectiva, uma "linguagem da vida real" (Marx, 1986:55) e é nesse sentido que na $\mathrm{AD}$ não se faz a história das representações, dos discursos, desligando-os dos fatos reais, do desenvolvimento de uma dada formação social, da prática social em que foram produzidos. Na AD, trata-se de "observar os modos de construção do imaginário necessário na produção dos sentidos" (Orlandi, 1992:18). Trata-se de analisar e interpretar a historicidade do discurso, compreender como a materialidade discursiva produz sentidos.

7 Conforme explicita Orlandi (1996:25-29), "A AD trabalha no entremeio, fazendo uma ligação, mostrando que não há separação estanque entre a linguagem e sua exterioridade constitutiva. [...] Não partimos, como na análise de conteúdo, da exterioridade para o texto, ao contrário, procuramos conhecer esta exterioridade pela maneira como os sentidos se trabalham no texto, em sua discursividade. É afinal esta noção de exterioridade que, ao se especificar na AD, transforma a noção de linguagem, pensando sua forma material, deslocando também a própria noção de social, de histórico, de ideológico, tal como estas noções estão definidas no domínio das ciências humanas e sociais." 
O discurso, assim compreendido, se revela como uma particularidade que cumpre a sua função no processo de constituição, produção e reprodução da vida em sociedade. A substância dessa particularidade (o discurso), que o faz diferente de outros particulares, está na indissociabilidade entre a língua e a história.

A língua é aqui compreendida no sentido empregado por Pêcheux: "Isto é, nem linguagem, nem fala, nem discurso, nem texto, nem interação conversacional, mas aquilo que é colocado pelos lingüistas como a condição de existência (de princípio), sob a forma da existência do símbolo" (Pêcheux, 1990:50). Língua, nesse sentido, é "base comum de todos os processos discursivos" (Orlandi, 1992:19).

A noção de história que cabe nessa reflexão é a que se desenvolve a partir da concepção de Marx (1986:55):

Esta concepção de história consiste pois, em expor o processo real de produção, a partir da produção material da vida imediata; e em conhecer a forma de intercâmbio conectada (ou seja, a sociedade civil em suas diferentes fases) como o fundamento de toda história, apresentando-a em sua ação enquanto Estado e explicando a partir dela o conjunto dos diversos produtos teóricos e as formas de consciência religião, filosofia, moral etc.

Por 'processo real de produção' entenda-se a complexidade das relações mutuamente dependentes entre natureza, trabalho $e$ organização social (Hobsbawm, 1998), o que significa reconhecer no 'processo real de produção' a imbricação da força física com a força intelectual dos sujeitos. Nessa concepção a história se constitui em relação contínua e permanente com as formações ideológicas que coexistem e se confrontam em uma dada formação social, considerando-se todas as 'formas' pelas quais se reproduzem essas formações ideológicas, especialmente o discurso. $O$ argumento decisivo para a concepção materialista de história é a relação fundamental entre objetividade e subjetividade, expressa nessa assertiva de Marx (1983:24): "Não é a consciência dos homens que determina o seu ser; é o seu ser que inversamente determina a sua consciência".

Os procedimentos teóricos e metodológicos para a análise do objeto do nosso estudo estão orientados por essa concepção de língua e história e se desenvolvem em dois caminhos que se intercruzam: a análise dos dados lingüísticos e as condições de sua produção, o que 
resulta na compreensão do funcionamento de um discurso dado em dadas condições de produção (história). Considerando que discurso é o "lugar do encontro" da materialidade da língua com a materialidade da história, é nesse encontro que as formações ideológicas se concretizam, se realizam e operam nas relações sociais. Assim. esse "lugar" onde língua e história constituem uma relação indissociáiel. corresponde à materialidade do discurso, bem como ao processo de produção do sentido, que, conforme vimos, "é determinado pelas posições ideológicas que estão em jogo no processo sócio-histórico" (Pêcheux, 1988:160).

Conforme vimos, as condições de produção do discurso estão diretamente relacionadas às formações ideológicas que se manifestam nos processos discursivos de uma dada formação discursiva. Estas formações discursivas, por sua vez, se constituem a partir de um mecanismo de dissimulação de sua dependência de algo já dito antes e $\mathrm{cm}$ outro lugar, "sob a dominação do complexo da formação ideológica" (Pêcheux, ibidem). Esse 'algo já dito antes e cm outro lugar', que não aparece imediatamente na superfície discursiva, $\dot{c}$ contudo, identificado a partir das marcas lingüísticas do funcionamento discursivo, de onde podemos partir para compreender o que Pêcheux chama de "todo complexo com dominante" ou interdiscurso. É identificando os discursos que se articulam no interior de uma formação discursiva que poderemos compreender os efeitos de sentido produzidos no funcionamento discursivo, e,

A expressão "articulam" aproxima-se da noção de "articulação" empregada por Pêcheux (1988:162), cuja formulação se refere a um dos elementos que permitem o funcionamento do interdiscurso; esses elementos são o pré-construido e a articulação, que "aparecem determinando o sujeito, impondo-dissimulando-lhe seu assujetiamento sob a aparência da autonomia, isto é, através de estrutura discursiva da forma-sujeito." A articulação representa, no interdiscurso, aquilo que determina a dominação da forma-sujeito e está em relação direta com o que Pêcheux chama de "discurso transverso". Então o interdiscurso se constitui enquanto discurso transverso (articulação) e enquanto préconstruido: "o interdiscurso enquanto discurso transverso atravessa e põe em conexão entre si elementos discursivos constituidos pelo interdiscurso enquanto pré-construído, que fornece, por assim dizer, a matérra-prima na qual o sujeito se constitui como sujeito falante', com a formação discursiva que o assujeita." (ibidem, p. 167). 
conseqüentemente, o processo de interpelação dos sujeitos pela ideologia representada por tal formação discursiva.

Observemos que foram introduzidos nessa parte do nosso trabalho três conceitos fundamentais para o processo de análise do discurso: formação ideológica, formação discursiva e interdiscurso. Tratemos de cada um separadamente.

\section{Formação ideológica}

Diferentes idéias e proposições convivem e se confrontam em um determinado momento histórico da sociedade para sua produção/reprodução (conservação e ou transformação das relações fundamentais da sociedade - relações sociais e econômicas). Essas idéias e proposições não se sobrepõem ao mundo material, aos fatos econômicos; elas constituem a instância ideológica do processo de produção e reprodução dos homens em sociedade, como o demonstramos no início desse capítulo, a partir da concepção de determinação.

A produção e reprodução da existencia dos homens em sociedade é um processo que se dá a partir de posições teleológicas ${ }^{9}$ que são uma especificidade do ser social, visto que só o homem, diferentemente dos seres orgânicos e inorgânicos, é capaz de atribuir e planejar finalidade para as suas ações. Pelo fato de essa capacidade ser inerente e peculiar ao homem [capacidade de pré-estabelecer um fim para os seus atos, de ter prévia-ideação na busca de alternativas para responder às suas necessidades], é que o ser social vai se complexificando, pois reproduz sempre o novo.

Num primeiro momento do ato teleológico, o homem intervém c transforma a natureza para responder à sua necessidade primeira de sobrevivência (comer e proteger-se dos efeitos naturais sobre o seu corpo). Trata-se da "posição teleológica primária", aquela em que o homem, mediado pelo trabalho, transforma a natureza e é por ela transformado em função da sua sobrevivência. À proporção que as necessidades são respondidas, surgem novas necessidades, as respostas a essas necessidades também vão-se diversificando e tornando-se mais

No sentido atribuido por Lukács (1979:17) como prévia-ideação, capacidade de antever o resultado com o planejamento da ação. 
complexas. Assim, as posições teleológicas se diversificam porque os homens precisam organizar sua processualidade, intervir no comportamento dos outros homens, provocar mudanças e responder às exigências postas pela complexidade com que o ser social vai se estruturando. Essas posições teleológicas que orientam as ações dos homens entre si são as "posições teleológicas secundárias". Posições teleológicas primárias e posições teleológicas secundárias se interligam no processo de produção e reprodução da vida em sociedade.

Contudo, cada uma dessas posições teleológicas tem seu objeto de intervenção próprio. O objeto da "posição teleológica primária" é a natureza, transformada por meio do trabalho, categoria fundante do ser social. O objeto da "posição teleológica secundária" são os homens com suas ações laborativas e extra-laborativas. A função dessa teleologia secundária é induzir os homens a assumirem posições frente às exigências do processo de produção e reprodução de sua existência.

A teleologia é um ato meramente individual: são os homens, enquanto indivíduos (e aqui não se pode conceber indivíduo sem sociabilidade, o indivíduo é já o indivíduo social), que produzem idéias, que elaboram as representações do mundo, que pensam. É das posições teleológicas secundárias, das quais se instituem 'mecanismos de orientação' para as relações entre os homens no processo de produção e reprodução da vida, que surge a ideologia. É nesse sentido que podemos entender a afirmação de Bakhtin (1992a:35): "a ideologia não pode derivar da consciência, como pretendem o idealismo e o positivismo". A consciência, por sua vez, "adquire forma e existência nos signos criados por um grupo organizado no curso de suas relações" (ibidem). ${ }^{10}$ Assim, princípios filosóficos, por exemplo, só se transformam em ideologia quando exercem ação sobre a prática social dos homens e orientam seu movimento para determinados fins, como o de manter a ordem social estabelecida, ou transformá-la.

Ideologia é aqui concebida como um processo de produção das formas de representação, das idéias e valores que constituem o fundamento operacional de uma prática específica, mobilizando e

10 Tomando-se os signos no sentido mais amplo, podemos entender que desses signos criados pelos homens surjam as formas específicas de organização da linguagem e manifestação da ideologia, os processos discursivos, por meio dos quais as consciências individuais e coletivas se manifestam, tomam forma e atuam na realidade. 
conferindo um caráter ético e político a essa prática. ${ }^{11}$ Nesse sentido, a ideologia não se define como um conjunto de idéias que estaria acima do mundo, dos fatos econômicos em especial; a ideologia se define como uma instância determinada no processo histórico-social de uma dada formação social. Na sociedade capitalista, seu funcionamento se dá nas relações sociais de produção, a ponto de abranger as determinações de classe e os horizontes culturais dos seus integrantes. Esse funcionamento da ideologia

consiste no que se convencionou chamar de interpelação [...] do sujeito em sujeito ideológico, de tal modo que cada um seja conduzido, sem se dar conta, e tendo a impressão de estar exercendo sua livre vontade, a ocupar o seu lugar em uma ou outra das duas classes sociais antagônicas do modo de produção (Pêcheux \& Fuchs, 1993:166).

Esse processo de constituição dos indivíduos em sujeitos não ocorre de uma única forma, em condições iguais para todos os homens da sociedade, mas através de um conjunto complexo e diversificado de formas pelas quais opera a ideologia. A diversidade de formas tomadas pela ideologia consiste em formas específicas de ideologia (como o direito, a religião, a política) ao que reconhecemos sejam as formações ideológicas, conforme definem Pêcheux \& Fuchs (ibidem). As formações ideológicas intervêm nas relações sociais como uma força em confronto com outras forças no interior da conjuntura ideológica de uma dada sociedade. Cada formação ideológica estabelece um complexo de valores, atitudes e representações historicamente definido em relação às classes em confronto ${ }^{12}$

11 Estamos formulando uma definição de ideologia a partir da formulação de Jameson (1997:19) - "uma teoria operacional de uma prática específica, como se fosse uma 'filosofia' desta última, e o conjunto de valores e visões que mobilizam e lhe conferem uma ética e uma política" explicitada para demonstrar que "toda ciência projeta não só uma ideologia, mas um certo número de ideologias", entendido em seu sentido positivo, o que põe a antiga distinção entre ciência e ideologia em revisão.

12 De modo particular, a classe de maior confronto com a burguesia, na leitura de Marx, no século XIX, era o proletariado - operariado. Hoje, a reestruturação produtiva dá uma outra configuração às classes que vivem do trabalho; estas não são constituídas especificamente de operários, trabalhadores das indústrias, mas de um novo contigente de trabalhadores gerado pelo desenvolvimento tecnológico neste final de século. 
As formações ideológicas, pois, são expressões da conjuntura ideológica de uma formação social; elas se põem historicamente de formas diferentes e em diferentes momentos históricos acompanhando o processo de complexificação da sociedade e, com ele, também se modificando. Assim, as formações ideológicas dominantes em uma sociedade correspondem ao modo de produção dominante. Nas palavras de Marx (1986:72) essa questão é assim explicitada: "a classe que é a força material dominante da sociedade é, ao mesmo tempo, sua força espiritual dominante", seus valores, atitudes e representações.

Assim é que se pode compreender porque na sociedade capitalista, constituída fundamentalmente pela relação de dominação da classe burguesa, as formações ideológicas dominantes são retratadas sobre a figura do capital e dos valores dessa ordem. As relações estabelecidas sob essa ordem (capitalista), pois, se efetivam no embate das duas formações ideológicas fundamentais - a do capital e a do trabalho - em função de interesses divergentes.

\section{Formação discursiva}

Cada formação ideológica que, historicamente, surge na sociedade tem como seus principais componentes uma ou mais formações discursivas, que veiculam as idéias, que definem o que ć permitido, ou não, dizer em uma dada realidade, para que determinados interesses sejam alcançados, sejam interesses de manutenção ou de transformação dessa realidade. As formações discursivas são, assim, meios pelos quais as formações ideológicas se manifestam como função social, intervindo nas relações e na prática social; são, por isso, 'sítio de significações' ${ }^{13}$, espaço de regulação e de confronto de muitos dizeres, que tanto podem apontar para uma mesma formação ideológica como para o confronto entre duas formações.

Assim, podemos entender as formações discursivas como sendo o lugar em que as formações ideológicas operam regulando os sentidos e estabelecendo o que pode e deve ser dito. "Isso eqüivale a dizer que as palavras, expressões, proposições etc., recebem seu sentido da formação discursiva na qual são produzidas [...], formações

13 Expressão devida a Orlandi (1998:13). 
discursivas que representam na linguagem as formações ideológicas que thes são correspondentes" (Pêcheux, 1988:160). Elas estão cm constante movimento, em permanente "processo de reconfiguração", "gestos de interpretação, de significação" (Orlandi, 1996).

Fsse movimento contínuo de reconfiguração e de significação tanto aproxima os sentidos, estabelecendo-os e determinando-os, lazendo parecer que, por isso, as formações discursivas são "regiões lechadas e estabilizadas". como os afasta e possibilita a manifestação do diferente. do confionto de sentidos em uma formação discursiva. As formações discursivas são "pontos de atracagem" que possibilitam esse processo de aproximação e distanciamento entre os sentidos dos processos discursivos, não permitindo que haja uma total independência entre eles, como não os deixando confundirem-se com outros sentidos já sedimentados na memória discursiva (no interdiscurso). "l é isto que dá identidade ao sujeito e ao sentido. lisses pontos de atracagem - que não são apenas pontos, mas formações - têm a forma histórica dos mecanismos ideológicos que se imprimem na relação com o simbólico. Não são jamais únicas mas sempre plurais, diferentes" (Orlandi, 1997:11).

Ora, no processo histórico-social de una sociedade de classes podemos observar o "desempenho" das formações discursivas para fazer valer ou fortalecer uma dada formação ideológica, seja do ponto de vista do capital. seja do ponto de vista do trabalho. Os interesses antagonicos das classes permitem aos sujeitos assumir posições divergentes, posicionar-se através das formações discursivas. Por isso, reconhecemos essas formaçōes discursivas como processos de constituiçào, que permitem ao sujeito assumir um lugar na sociedade, posicionar-se no embate ideológico que se mantém sobre a base da produção economica dominante da época, seja rejeitando ou reforçando esse estado da sociedade. Assim, quando o sujeito expressa suas idéias. elas estão entranhadas das formas ideológicas que perpassam a posição desse sujeito na sociedade. Os sujeitos empregam palavras e expressões marcadas pela posição que assumem frente à diversidade política e ideológica, que estão em permanente confronto na socicdade.

As formações discursivas, por serem formas em que as formações ideológicas se manifestam e podem concretizar-se enquanto função social, estão em permanente movimento, em 
contínuo processo de reconfiguração, aproximando ou distanciando os sentidos que se propõem sejam veiculados em uma dada conjuntura para a manutenção da sua ordem ou para sua ruptura.

Dizer que as palavras são a forma concreta, possivel de organização e manifestação das formações discursivas, parece a afirmação do óbvio. Entretanto, não é o óbvio dizer que não se limitam a palavras linearmente postas em uma seqüência lingüística, ${ }^{1+4}$ mas são palavras que produzem processos de funcionamento discursivo, que articulam e produzem sentido, no constante movimento parafrástico ${ }^{15}$ que ocorre no interior de uma formação discursiva, constituindo-se em processos discursivos.

Os sentidos das palavras só são reconhecíveis na medida em que se compreende a sua vinculação com uma dada formação discursiva. Daí reconhecer-se, na $\mathrm{AD}$, que as formações discursivas são as "matrizes" de produção de sentido porque no seu interior se dá o intercruzamento de paráfrases (ao que, na AD Fuchs \& Pêcheux, 1993, chamam de famílias parafíásticas) que produzem efeitos de sentido. Pelo fato de o sentido das palavras, ou expressões, só ser reconhecido em relação à formação discursiva na qual estão engajadas, e, sendo essas formações discursivas formas de manifestação das formações ideológicas, é que se pode explicar que essas palavras e expressões não tenham um único sentido. Uma mesma palavra terá sentidos diferentes quando inscrita em formações discursivas diferentes, enquanto diferentes palavras terão o mesmo sentido quando inscritas em uma mesma formação discursiva. A produção do sentido estará, assim, relacionada com a posição ideológica que aquela formação discursiva representa no processo histórico.

Assim, compreendendo que o que significa não são as palavras em si, mas a sua realização em enunciados, podemos afirmar

14 Pêcheux propõe para a $\mathrm{AD}$ que a cada seqüência lingüística corresponda uma representação dessuperficializada - o que responderia ao efeito de ocultação parcial (esquecimento 2), efeito gerado pelo processo de seleção do que é permitido dizer ou não dizer, em uma dada conjuntura; esse efeito é próprio das formações discursivas (Pêcheux \& Fuchs, 1993: 205).

15 Cf. Orlandi (1998), sobre a relação da formação discursiva com o simbólico e o movimento entre paráfrase e polissemia, que constitui o processo de reconfiguração das formações discursivas. 
que a significação se instaura, enfim, em uma instância da enunciação, na instância do discurso. Se a unidade material do discurso é constituída pela relação constitutiva da língua com a história, como já vimos no início desse capítulo, podemos avançar nessa reflexão entendendo que o discurso é tecido por uma multiplicidade de fios ideológicos (Bakhtin, 1992a) que dão o "tom" das diferenças entre formações discursivas, nas quais se constituem, se articulam e se ancoram os discursos.

\section{Interdiscurso}

Ao considerarmos o movimento que aproxima e distancia uma formação discursiva de outras, podemos compreender que os discursos não são idênticos entre si; são o resultado de um processo interdiscursivo - a combinação (levando-se em conta a natureza contraditória dos processos combinatórios) de mais de um discurso dentro de uma mesma formação discursiva. É esse processo que permite a diferença entre os discursos ao mesmo tempo que os aproxima.

O interdiscurso é o já existente, o dizivel, que é exterior ao sujeito do discurso (memória histórica). Segundo Orlandi (1998:12), "o interdiscurso se apresenta como séries de formulações que derivam de enunciações distintas e dispersas que firmam em seu conjunto o domínio da memória (do saber discursivo); esse domínio constitui a exterioridade discursiva para o sujeito do discurso." Essa noção de interdiscurso está apoiada na noção desenvolvida por Pêcheux (1988) a partir da noção de pré-construído proposta por Henry. Segundo Pêcheux (1988:99), o termo "pré-construido" é empregado pelo referido autor "para designar o que remete a uma construção anterior. exterior, mas sempre independente, em oposição ao que é construído pelo enunciado." Essa noção de pré-construído trata, originariamente, do efeito discursivo ligado ao fenômeno sintático, à forma de organização da língua.

Para Marandin (1997:130), a noção de pré-construido "foi proposta com um objetivo bem particular: conceber a eficácia própria da linguagem, quer dizer, uma eficácia que não possa ser atribuída à ação ou às intenções de um locutor. Ela se apresenta então como fundadora de uma pragmática não-subjetiva." Pretendia-se, com a 
noção de pré-construido, chegar a um ponto de análise da linguagem que garantisse as exigencias de objetividade impostas pelas ciencias positivistas. Haveria um discurso já dado, independente do que estarıa sendo enunciado - discurso atual. Haveria. contudo, uma relação entre esses discursos que não se efetivaria pela vontade do sujeito e seria essa "não subjetividade" que garantiria a eficácia própria da linguagem. Nesse sentido, a noção de pré-construido. base da noção de interdiscurso, não se restringe ao sentido que o sujeito dá ao dizivel, mas ao sentido do dizivel, "seu efeito referencial, sua objetividade" (Orlandi, 1998:12).

Mas, ao retomar a noção de pré-construído, Pêcheux (1975) procura introduzir essa discussão em uma teoria materialista dos processos discursivos e vai encontrar a possibilidade de explicitar uma teoria "não subjetiva" da subjetividade, de reconhecer o sujeito nos processos discursivos (Pêcheux. 1988:130-31). O que significa dizer que uma teoria não subjetiva do discurso não necessariamente teria que aniquilar o papel do sujeito na sua produção para garantir o critério de objetividade requisitado pela ciência. O sujeito tem um papel na produção do discurso, mas seu reconhecimento não levaria ao seu enaltecer, à sua elevação ao patamar da fonte constituída de todos os sentidos. Tomar o sujeito como ponto de partida e ponto de aplicações de operações (ponto de chegada) seria uma solução idealista prejudicada, segundo Pêcheux (1988:130), pela noção ideológica de sujeito, o sujeito individual 'concreto'."

Para Pêcheux, o sujeito é efeito da interpelação ideológica. "o não sujeito é interpelado-constituido em sujeito pela Ideologia" [com letra maiúscula]. Pela ideologia o indivíduo se torna sujeito, passa a ter uma existência histórica, passa a ser "ator social". Em outras palavras, o indivíduo se constitui em sujeito nas relações históricosociais, que são particularmente permeadas pela luta de classes e, por conseguinte, pela ideologia. A constıtuição do sujeito se efetua pela relação desse sujeito com as formações ideológicas que estão em permanente confronto no processo sócio-histórico. A ideologia interpela o sujeito por meio da formação discursıva, que é impregnada

16. Para Pêcheux, o sujeito não é o "individuo", o sujeito se constitui na relação entre linguagem e ideologia. Sobre as diferentes concepções de sujeito entre a produção de Pêcheux e de pensadores como Iacan, Foucault e Derrida, cf. Henry, 1993. 
por un universo de conceitos, de definições, de elaborações teóricas acerca das coisas, da estrutura da realidade, das formas como essa realidade se apresenta. "O 'sempre-já-dito' 'fornece-impõe' à 'realidade' o seu sentido sob a forma de universalidade". o que Pêcheux (1975) denomina de pré-construido. Então, para Pêcheux (1988:102), a característica decisiva do pré-construido é

a separação fundamental entre o pensamento e o objeto de pensamento, com a pré-existência desse último, marcada pelo que chamamos uma discrepância entre dois dominios de pensamento, de tal modo que o sujeito encontra um desses dominios como o impensado de seu pensamento, impensado este que necessariamente pré-existe ao sujeito. ${ }^{17}$

O sujeito inscreve em seu discurso "traços" (pontos característicos que qualificam e distinguem uma formação discursiva de outra) da formação discursiva que o domina e com a qual se identifica, estabelecendo-se como "forma-sujeito do discurso". Com essa compreensão de pré-construido, Pêcheux não desqualifica o sujeito no processo discursivo; na realidade, o dizer do sujeito se realiza quando esse sujeito se inscreve no já dito. É incorporando elementos pré-construidos que o sujeito coloca a sua "marca" no discurso.

Nesse processo de incorporar o já dito e reapresentá-lo como diferente, segundo Orlandi (1998:12), operam dois processos: o interdiscurso e o intradiscurso ${ }^{18}$. $\mathrm{O}$ interdiscurso incorpora elementos do pré-construído e regula a possibilidade dos sentidos do enunciado: nào permite que se perca o efeito referencial ${ }^{19}$ do enunciado. a sua objetividade. $O$ intradiscurso permite que o sujeito intervenha no enunciado, no repetivel: é da esfera da formulação do sujeito: é o que possibilita re-significar o já dito e se significar.

Pêcheux explicita o paradoxo dessa separação: "o motor do processo pelo qual se pensa o objeto de pensamento" (1988:102), o que no nosso entender resulta no concreto pensado, a transformação da realidade no pensamento, um processo de abstração que só é possivel com a linguagem.

Is Sobre esses conceitos, cf. tb. Courtine, 1981

11) A expressão efeito referencial é empregada por Orlandi no sentido de reafirmar que o objeto tem "um sentido" que não é necessariamente o sentido dado pelo sujeito, não é qualquer sentido que se atribui ao objeto. mas os que por ele são autorizados; dai a sua objetividade. 
Compreendemos, assim, que é por esses dois domínios, o do inter e do intradiscurso, que o discurso é produzido e aparece como um resultado. O discurso é, assim, a síntese de muitas determinações; uma unidade da diversidade não é então, simplesmente, a manifestação da língua enquanto um sistema de regras que impõe uma seqüência ordenada a um conjunto de palavras até então dispersas. O discurso é, como diz Maldidier (1997:82),

Uma prática resultante de um conjunto de determinações reguladas em um momento dado por um feixe complexo de relações com outras práticas, discursivas e não-discursivas. Este complexo de relações para nós, deve ser estabelecido no quadro do conjunto articulado dos conceitos do materialismo histórico.

O discurso é um "fenômeno integral concreto" (Bakhtin, 1997:182), uma enunciação concreta; concreta porque as condições de sua produção, seus mecanismos para provocar efeitos de sentido e realizar mudanças nas relações entre os homens, a sua significação enfim, é determinada pelas condições sociais e econômicas da época. É histórica.

Restaria, então e enfim, considerar que o processo de produção do discurso ocorre em determinadas condições em que opera a relação entre o real e o pensamento, formando um "complexo" que se instaura sobre determinadas modalidades histórico-materiais discursivas:um complexo do conjunto de formações discursivas e formações ideológicas de uma dada formação social. Assim, o discurso é uma objetividade, forma concreta do ser, esse "algo" que a consciência reflete. O trabalho de interpretação do discurso, pois, ocorre a partir de um longo e árduo trabalho de análise das condições objetivas em que esse discurso foi produzido; é o próprio discurso que oferece as pistas para que se possam conhecer as condições sóciohistóricas de sua produção e os efeitos de sentido por ele produzidos. 


\section{REFERÊNCIAS BIBLIOGRÁFICAS}

BAKHTIN, Mikhail. Marxismo e filosofia da linguagem. São Paulo: Hucitec, 1992a

BAKHTIN, Mikhail. Estética da Criação Verbal. São Paulo: Martins Fontes, 1992b.

BAKHTIN, Mikhail. Problemas da poética de Dostoiévski. Rio de Janeiro: Forense Universitária, 1997.

CHASIN, José. O integralismo de Plinio Salgado. São Paulo: Ciências Humanas, 1978.

CHASIN, José. Lukács: vivência e reflexão da particularidade. Ensaio n.9. São Paulo: Ensaio, 1982.

COURTINE, Jean-Jacques. Quelques problèmes theóriques et méthodologiques en analyse du discours: à propos du discours comuniste adressé aux chrétiens. Langages, Paris, Larousse, n.62, p. 9127, 1981.

HENRY, Paul. Construções relativas e articulações discursivas. Cadernos de estudos lingïísticos, 19. Org. Eni Orlandi e João Wanderley Geraldi. Campinas, Editora da Unicamp, 1990.

HENRY, Paul. Sentido, sujeito, origem. In: ORLANDI, Eni (org.). Discurso fundador; a formação do país e a construção de identidade nacional. Campinas: Pontes, 1993, p. 151-165.

JAMESON, Frederic. O marxismo tardio: Adorno, ou a persistência da dialética. São Paulo: Fundação Editora da UNESP e Editora Boitempo, 1997.

LUKÁCS, Georg. Ontologia do ser social: os princípios ontológicos fundamentais de Marx. São Paulo: Editora Ciências Humanas, 1979.

MAINGUENEAU, Dominique. Novas tendências em análise do discurso. 2. ed. Campinas: Pontes, 1993. Original de 1987.

MALDIDIER, Denise et al. Discurso e Ideologia: base para uma pesquisa. In: ORLANDI, E. (org.). Gestos de Leitura. Campinas: Editora da Unicamp, 1997. p. 67-102. 
MARANDIN, Jean-Marie. Sintaxe, discurso: do ponto de vista da análise do discurso. In: ORLANDI, E. (org.). Gestos de Leitura. Campinas: Editora da Unicamp, 1997. p. 19-144.

MARX, K \& F ENGELS. A ideologia alemã. São Paulo: Hucitec, 1986.

MARX, Karl. Contribuição à crítica da economia politica. São Paulo, Martins Fontes, 1983.

ORLANDI, Eni. As formas do silêncio: no movimento dos sentidos. Campinas: Editora da Unicamp, 1992.

ORLANDI, Eni. Interpretação, autoria, leitura e efeitos do trabalho simbólico. Petrópolis: Vozes, 1996.

ORLANDI, Eni (org.). A leitura e os leitores. Campinas: Pontes, 1998. A leitura proposta e os leitores possiveis.

PÊCHEUX M. \& FUCHS,C. A propósito da análise automática do discurso: atualização e perspectivas. In: GADET, F. \& HAK, T. (orgs.). Por uma Análise Automática do Discurso. Uma introdução à obra de Michel Pêcheux. 2. ed. Campinas: Editora da UNICAMP, 1993.

PÊCHEUX, Michel. Semântica e Discurso, uma crítica à afirmação do óbvio. Campinas: Editora da Unicamp, 1988. Original de 1975.

PÊCHEUX, Michel. O discurso. Estrutura ou acontecimento. Campinas: Pontes, 1990.

WILliAMS, Raymuond. Marxismo e literatura. Rio de Janeiro: Zahar, 1979. 